\section{CLINICAL} REFLECTION

\title{
Methodological dualism considered as a heuristic paradigm for clinical psychiatry
}

\author{
Tuomas K. Pernu (1)
}

\begin{abstract}
Tuomas K. Pernu is a lecturer in philosophy of science and research ethics at the University of Eastern Finland, Joensuu and Kuopio, Finland, and a former research fellow at the Helsinki Collegium for Advanced Studies, University of Helsinki, Finland. He is also a research associate on the Philosophy \& Medicine project in the Department of Philosophy, King's College London, UK. A key aim of the project is to introduce philosophy into medical school curricula.

Correspondence: Tuomas K. Pernu. Email: tuomas.pernu@uef.fi
\end{abstract}

First received 26 May 2021 Final revision 10 Aug 2021 Accepted 21 Aug 2021

\section{Copyright and usage}

(C) The Author(s), 2021. Published by Cambridge University Press on behalf of the Royal College of Psychiatrists. This is an Open Access article, distributed under the terms of the Creative Commons Attribution licence (https://creativecommons. org/licenses/by/4.0/), which permits unrestricted re-use, distribution, and reproduction in any medium, provided the original work is properly cited.

\section{SUMMARY \\ Debates on dualism continue to plague psychiatry. I suggest that these debates are based on false dichotomies. According to metaphysical physical- ism, reality is ultimately physical. Although this view excludes the idea of entities distinct from physical reality, it does not compel us to favour neural over psychological interventions. According to methodological dualism, both physical and mental interventions on the world can be deemed effective, and both perspectives can therefore be thought to be equally 'real'. \\ KEYWORDS \\ Causal explanation; dualism; mind-body problem; physicalism; reductionism.}

Two things make psychiatry unique among the sciences. First, psychiatry occupies an uneasy place between the physical and the mental ways of viewing the world. This is something that psychiatry has in common with psychology and the neurosciences, or 'the cognitive sciences' in general. Second, psychiatry is not simply disinterested, purely academic study of the body and the mind, but a discipline whose aim is distinctly pragmatic: to provide effective treatments to those who are suffering. This is something that psychiatry has in common with other essentially pragmatic disciplines, medicine in particular. What makes psychiatry unique is the way that its pragmatic goal lies at the intersection of two radically different ways of viewing the world; psychiatrists are, as it were, physicians operating in a non-physical realm.

No wonder, then, that debates concerning dualism continue to creep up in psychiatry. Recently, for example, in BJPsych Advances Ng (2021) has defended the possibility of a dualistic interpretation of psychiatry against the suggestion of Novick $\&$ Ross (2020) that psychiatry would benefit from a more intimate alignment with the neurosciences. So, which one is it: should psychiatry be viewed as an inherently dualistic discipline, or is the proper place of psychiatry among the neurosciences?
This is a false dichotomy, I suggest, and I outline here a way out of it - a third option that takes both our dualistic practices and our physicalist, scientifically based intuitions into account. I call this view 'methodological dualism' (first introduced as a term by Pernu \& Elzein 2020).

\section{Dualism(s) and physicalism(s)}

Although the term 'dualism' appears often in philosophical discussions on psychiatry, it anything but clear what the notion really amounts to (Maung 2019). All forms of dualism hold on to some sort of 'distinctness' of the mental and the physical, but there is consensus neither on what the things are that are supposed to be distinct, nor on what their 'distinctness' amounts to. Here, 'methodological dualism' refers to the following thesis:

\section{The physical and the mental are conceptually and methodologically distinct; both physical and mental ways of intervening on mental health conditions can} be found effective.

Let us hold unproblematic what 'mental' amounts to: that it is something intentional, conscious and goal-directed (Pernu 2017). How should we understand 'physical'?

The terms 'physical' and 'material' are often used interchangeably (e.g. Ng 2021). In current philosophy, however, these terms are typically kept distinct: the term 'material' refers to an intuitive, everyday, 'folk-physical' way of perceiving the world - as objects colliding into each other, pushings and pullings, and so on - whereas the term 'physical' refers to a more precise, scientific understanding of how the world works. Basically, physicalism is the view that the science of physics tells us what the ultimate constituents of reality are.

Now, for the purposes of this discussion, we can define the thesis of metaphysical physicalism thus:

All of reality is physical; what we should hold fundamentally real is determined by the science of physics.

According to this monistic (anti-dualistic) metaphysical view, all of reality is fundamentally or ultimately physical. It amounts to the idea that if 
you take all we deem as physical in this world (all the space-time points of the universe), and duplicate it to create another world, you will duplicate everything in this world: a complete physical description of reality is a description of all there is.

Metaphysical physicalism is perfectly compatible with methodological dualism: one can hold that all of reality is ultimately physical, while at the same time claim that the mental and the physical are conceptually and methodologically distinct and that both of them can provide us with efficacious ways of intervening on the world. Indeed, I think this is precisely the way scientifically informed people, laypeople and healthcare professionals alike, perceive the relationship.

More precisely, reconciling methodological dualism with metaphysical physicalism amounts to the thesis that the system encompassing humans and their interactions (societies) forms a proper subsystem of the physical universe. This should be as uncontroversial a claim as it gets: nobody, ever, has held the view that humans - the physical objects of human bodies or their brains - would exhaust all of the physical reality. Everybody agrees, therefore, that from the physical point of view humans, along with their bodies and their brains, form a proper subset of all of reality. This, in any case, is what follows from metaphysical physicalism.

Does physicalism, as it has been here defined, entail mind-brain reductionism, or the idea that the mind and the brain are identical? The unequivocal answer is: no. How is this? Well, it was just established that brains are a proper subset of reality - all that we consider physically real. That is, all that we hold 'physically real' is everything there is, but human brains are not everything. Therefore, and contrary to the widespread practice of conflating these notions (e.g. Novick 2020; Ng 2021), if you hold the mental identical with the physical - as you should if you subscribe to the thesis of metaphysical physicalism - you are not automatically committed to holding the mental identical with, or reducible to, the brain. What this entails, to be precise, is that minds and mental states must extend beyond the brains and neural states they are conventionally attributed to (Box 1).

\section{Psychiatry as effective interventions}

Let us now focus on the latter part of the definition of methodological dualism. Setting physics, and the abstract notion of metaphysical physicalism, aside we can say that medicine, and psychiatry as a proper part of it, is all about effective interventions: what is (medically) real is such in relation to the (medical) effectiveness of the interventions applied in medical contexts, or, more generally, in relation
BOX 1 Relational psychiatry

How can one say that metaphysical physicalism - the idea that everything is fundamentally physical - does not entail mind-brain reductionism, or the idea that the mind and the brain are identical? Surely, if everything is fundamentally physical, then all mental states and processes are fundamentally physical too, and where else in the physical world can one place the physical bases of these states and processes but in the brains and bodies of the organisms to which they have been attributed? Doesn't claiming the opposite amount to a blatant rejection of the science of neurobiology?

Note, first, that we find it not at all problematic to speak in psychological terms about a large variety of artificial systems: programs, computers and robots perceive, remember and act, and so on. If we think, as it seems that we do, that there is, or at least can be, such a thing as artificial intelligence, and if artificiality is, by definition, something nonbiological, or non-neural and non-bodily, then we are committed to the idea that mental states and processes can be real without being biological, neural or bodily. None of this entails that mental states and processes are nonphysical: everybody agrees that artificially intelligent systems are physical systems. What this does suggest, however, is that it is thoroughly misleading to identify mental states and processes with the material constitution of the entities to which we find it convenient to attribute them. Mental states and processes are not items or substances, be they physical or mental, but functional capabilities: they enable agents to operate in larger environmental contexts. Even if we limit our focus to entities we recognise as biological, it is anything but clear that mental states and processes should be identified with, or be reduced to, some internal (neural or bodily) states of such entities. In biology it is often inadequate, or an unfruitful idealisation at least, to treat organisms as insular entities cut off from other organisms and the environment. In medicine in particular, it is a very basic fact that the states and processes that we draw medical attention to (injuries, disorders, diseases, illnesses) are relational in nature. Not only do they result from interactions with conditions (harmful events, pathogens, exposure to risk factors) external to the organisms we designate as subjects of these states or processes - and this is as true for somatic medicine as it is for psychiatry: saying 'experiencing systematic abuse as an adolescent led her to suffer from depression and anxiety as an adult' is perfectly on a par with saying 'indulging in excessive smoking earlier in life led her to suffer from lung cancer later in life'. But more importantly, by identifying these states and processes as medically relevant - as injuries, disorders and so on, rather than as plain events - we are labelling them as dysfunctional or defective, as being in some sort of a mismatch in relation to how things ought to be. No medical condition is, therefore, such 'in itself', but only in relation to a specific context in which it makes sense to make comparisons between correct and incorrect ways of functioning.

What, then, defines the right sorts of contexts in which to make such comparisons? Perhaps many factors play into 
defining such contexts, but one seems central: reliable, repeatable interactions. In other words, the right sorts of contexts in which to judge whether something is dysfunctional or defective are those in which the thing under assessment is reliably responsive to a specific range of interventions: dysfunctional or defective things do not act as expected when intervened on, or when they interact with the environment in a normal way.

Mental states and processes - and the disorders of the mind - are responsive to psychological, behavioural and social cues. Neural states and processes - and the disorders of the brain - are not: you cannot talk a person out of a brain tumour. This is why we hold these two domains distinct from each other. But they are not wholly distinct, of course: both the neural and the mental belong to the physical world as its parts. It's just that they are distinct parts of it - precisely in the sense of being responsive to different kinds of physical states and processes.

to an environmental context considered medically relevant (Box 1). In psychiatry, both mental and physical ways of intervening on the world can be deemed effective (Pernu 2019).

Consider the following example. A person you know well, and deeply care about, feels that her neighbour has been watching her and, moreover, she claims that the neighbour has installed sophisticated surveillance equipment to monitor her every move. Suppose that this claim is not true, and consider two alternative scenarios for explaining why the person has these feelings:

(a) the person has been manipulated (by a third person) into thinking that the neighbour holds a grudge against her, and that he has taken all these measures to get even with her

(b) the person is delusional; there is no rational explanation for her beliefs.

How would you, as a friend, or as a psychiatrist, intervene in these scenarios? How would you try to make the person feel better? Clearly, in the first scenario, you would try to reason with her: you would try to talk her out of her beliefs. Now, as the person holds, in this case, rational and justified, albeit false, beliefs we can assume that your efforts to reason with her would bear fruit quickly, and that she would change the way she feels about her neighbour. In the second scenario, however, such interventions would not be successful: not only does the person hold false beliefs, but she has no rational justification for holding them, and there is no way to reason with her.

It is tempting to view these two alternative scenarios as in some fundamental way dichotomous, mutually exclusive - in a word: dualistic. In reality, however, they form two ends of a continuum of sources of distress people feel. At times, we all hold false, even strange beliefs that hinder our interactions with other people and cause us distress. This is normal, an everyday human condition. We can take the scenario in (a) as a caricature, extreme version of this. These situations are addressed by perfectly mundane psychological and social means - by talking to people. Sometimes, however, such interventions are not effective in relieving the distress, not by themselves at least, or not without a more systematic, long-term administration. We can take scenario (b) as representing such a case.

I do not mean to claim that our intuitive ways of responding to scenarios (a) and (b) map neatly to psychotherapy and pharmacotherapy respectively. Rather, I maintain that these cases illustrate a continuum of means we have at our disposal for intervening on mental disorders - means ranging from mental (psychological) to physical (pharmacological). It is difficult to see what psychiatry would have to gain from holding either that 'minds are just brains' or that 'minds and brains are distinct', but it is easy to see what it would have to lose if it were to maintain that either reasoning with people or treating them by pharmacological means would have to be excluded from the repertoire of interventions psychiatry recognises as valid.

\section{Conclusions}

Methodological dualism and metaphysical physicalism are compatible. What metaphysical physicalism finds problematic is the idea that the mental and the physical are wholly distinct from each other. What it does not have any quarrel with, however, is the assumption that different parts of physical reality can be in an interaction with each other - that, for example, people can engage in social interactions and reason with each other, and that this can influence their feelings and alter their behaviour. From this perspective, mental (in contrast to the physical) is as real as it gets. This is why methodological dualism should be deemed as the proper paradigm for clinical psychiatry.

\section{Acknowledgements}

I thank Dr Tom S. Ainscough, Dr Nadine Elzein, Dr Anneli Jefferson, Dr Allan Seppänen and an anonymous reviewer of BJPsych Advances for helpful comments and discussions on various versions of this article.

\section{Funding}

This research received no specific grant from any funding agency, commercial or not-for-profit sectors. 


\section{Declaration of interest}

None.

\section{References}

Maung HH (2019) Dualism and its place in a philosophical structure for psychiatry. Medicine, Health Care and Philosophy, 22: 59-69.

$\mathrm{Ng}$ CC-W (2021) Is mind-body dualism compatible with modern psychiatry? BJPsych Advances [Epub ahead of print] 4 Mar. Available from: https://doi.org/10.1192/bja.2021.20.
Novick AM, Ross DA (2020) Dualism and the 'difficult patient': why integrating neuroscience matters. BJPsych Advances, 26: 327-30.

Pernu TK (2017) The five marks of the mental. Frontiers in Psychology, 8 1084

Pernu TK (2019) Causal explanation in psychiatry. In The Bloomsbury Companion to Philosophy of Psychiatry (eds. Ş Tekin, R Bluhm): 21736. Bloomsbury Academic.

Pernu TK, Elzein N (2020) From neuroscience to law: bridging the gap. Frontiers in Psychology, 11: 1862 